\title{
Rapid Fault Diagnosis of Photovoltaic Panels Under Outdoor Environmental Conditions
}

\author{
Christian Schuss*, Kari Remes*, Kimmo Leppänen ${ }^{\dagger}$, Juha Saarela*, Tapio Fabritius* $^{*}$ Bernd Eichberger ${ }^{\ddagger}$, \\ and Timo Rahkonen ${ }^{\S}$ \\ * Optoelectronics and Measurement Techniques (OPEM) Research Unit, University of Oulu, Finland; \\ email: christian.schuss, kari.remes, juha.saarela, tapio.fabritius@oulu.fi \\ ${ }^{\dagger}$ Mettler-Toledo GmbH, SBU AutoChem, Switzerland; email: kimmo.leppanen@mt.com \\ $\ddagger$ Institute of Electronic Sensor Systems, Graz University of Technology, Austria; email: bernd.eichberger@tugraz.at \\ ${ }^{\S}$ Circuits and Systems (CAS) Research Unit, University of Oulu, Finland; email: timo.rahkonen@oulu.fi
}

\begin{abstract}
This paper investigates opportunities to rapidly detect defects in photovoltaic (PV) panels. It is worth noting that a defect in a single $P V$ cell can significantly reduce the output power of a PV panel and, thereby, of an entire PV array. Hence, it is crucial to detect faults in PV panels and replace them within PV power plants. In this paper, we utilise synchronized thermography (ST) to obtain infrared (IR) images under outdoor environmental conditions. We illustrate how IR-images obtained under changing irradiation and different angles can be analysed to rapidly detect defects in PV panels. Our technique allows maintenance staff to quickly identify PV panels with defects on the site of a $\mathrm{PV}$ power plant.

Index Terms - defect, fault diagnosis, infrared, outdoor environment, photovoltaic cell, photovoltaic panel, rapid diagnosis, solar energy, synchronized thermography.
\end{abstract}

\section{INTRODUCTION}

Forecasts estimate that the energy consumption of the world will increase by $56 \%$ between 2010 and 2040 . Over the same time period, it is forecasted that global energy-related carbon dioxide emissions will increase to 45 billion metric tons in 2040, which represents an increase of $46 \%$ compared to 2010 [1]. Solar energy is perceived as the most promising energy resource to counteract these negative future projections for humanity and to substitute non-renewable energy resources such as coal, oil, gas and nuclear power (COGN) energy sources [2], [3].

It is worth noting that the potential energy of photovoltaics directly depends not only on the available irradiation, but also on defects and faults, which can be caused by effects related to aging and different types of events and impacts over time. A defect in a single PV cell affects the output performance of the whole PV panel and, therefore, the output performance of an entire PV array [4]-[7]. For that reason, it is vital to detect faults and defects in PV panels and replace them accordingly. Thus, a measurement technique is needed which allows maintenance staff to locate a defect PV panel and replace that PV panel to improve the performance of the PV power plant [8].

Commonly, the output power and, thus the performance of $\mathrm{PV}$ panels is measured with the help of electrical verification to obtain the characteristic Current-Voltage $(I-V)$ curve of PV panels [9]-[11]. However, electrical verification can only be used to measure the $I-V$ curve of individual PV panels, but not of an entire array of a PV power plant. Thus, when carrying out electrical measurements, PV panels must be disconnected from each other. As a result, it takes significantly more time to carry out diagnosis on PV panels for potential defects. Here, infrared thermal (IRT) imaging techniques can be helpful to be used by maintenance staff on the site of the PV power plant to verify the performance of PV panels [12].

IRT imaging techniques such as lock-in thermography (LIT), electroluminescence (EL) imaging, photoluminescence (PL) imaging, synchronized thermography (ST), time-resolved thermography (TRT) and other IRT techniques are designed for imaging PV panels under indoor environmental conditions [13]-[17]. Recently, experiments were carried out with IRT techniques also to detect defects in PV panels under outdoor environmental conditions [18]-[20]. However, under outdoor environmental conditions such as irradiation can influence IRT techniques in various ways and, thus, the obtained measurement results [19], [20].

IR-cameras can be equipped to unmanned aerial vehicles (UAVs) to carry out diagnosis on the condition of PV panels within a PV power plant. IR-cameras including weather stations to measure ambient temperature, wind speed, relative humidity, horizontal irradiation can also be used to monitor PV power plants on a continuous basis [19]. However, in order to minimise the efforts and costs for detecting defects in PV panels, a simple IRT technique is needed which is independent of environmental conditions. Furthermore, the opportunity should be given that maintenance staff can carry out measurements on the site of the PV power plant with a portable low-cost IR-camera instead of an expensive stationary IR-camera which requires a certain alignment.

A portable IR-camera can also help to maximise the usage of the resolution of the camera by optimising the distance between the camera and PV panel [17]. In respect to the region-of-interest (ROI) [17], a stationary IR-camera is often used to measure several PV panels at the same time [19], [20]. By using an IR-camera for several PV panels simultaneously, only a fraction of the resolution is used for one PV panel and even a smaller share for one PV cell. Hence, as in [19], [20], only the temperature in approximately the centre of one PV 
cell is measured.

Based on this way of using the resolution the IR-camera, it is possible that the background irradiation as well as other factors can have various impacts on the result of the measurement, in particular the accuracy of the measurement. As an example, Akram et al. [18] report in their work that measurements conducted on PV panels outdoors do not result in the same results as measurements carried out indoors. More precisely, IR-images obtained outdoors show fewer or not all defects in PV panels in comparison to indoor measurements [18]. Likewise, Teubner et al. [19] report that weather conditions can affect the results of IR thermography. In their work, for measurements outdoors, steady-sate conditions are preferred in which the solar radiation level remains constant within a certain period of time [19].

In this paper, we wish to utilise a simplified version of ST, based on previous research [16], for rapid diagnosis on PV panels in order to detect defects under outdoor environmental conditions. With the help of our method, maintenance staff can quickly flag PV panels with potential defects. At the same time, by optimising the usage of the resolution of the IRcamera and, in this way, maximising the ROI, we aim to avoid false positive and false negative decisions whether a PV panel contains defects or not. Moreover, with the help of our technique, we also eliminate the necessity of a non-defect reference sample, needed in other comparable approaches [19].

\section{BACKGROUND OF THE RESARCH}

\section{A. Behaviour of Photovoltaics}

Commonly in PV simulation models, each PV cell in a panel is threated in the same way. In other words, each PV cell is simulated with the same values for all parameters. Furthermore, in commercial PV panels, all PV cells are connected in series with each other in order to achieve a high voltage level [21], [22]. However, if a single PV cell in the panel is defect, the output power of the entire PV panel is affected. In a series connection of PV cells, the short-circuit current $\left(I_{s c}\right)$ depends on the short-circuit current of the weakest PV cell of the interconnection $\left(I_{s c, \min }\right)$ [16], as obtained by the following equation

$$
\begin{array}{r}
P_{\text {ideal }}=V_{o c} \cdot I_{s c, \text { min }} \\
I_{s c, \text { min }}<I_{s c}
\end{array}
$$

where $P_{\text {ideal }}$ is the ideal power of the PV panel and $V_{o c}$ is the open-circuit voltage of the PV panel.

\section{B. Configuration of a PV panel}

Fig. 1 illustrates a typical series connection of PV cells in a commercial PV panel. The example, which is seen in Fig. 1 , is taken from a PV panel which contains $36 \mathrm{PV}$ cells and produces an output power of $80 \mathrm{~W}$. In each row, $9 \mathrm{PV}$ cells are located. At the end of each row, either on top or on the button of the PV panel, each string of PV cells is then connected to the next string of PV cells in the next row. The corner points are connected to a voltage terminal on which the output power can be obtained.

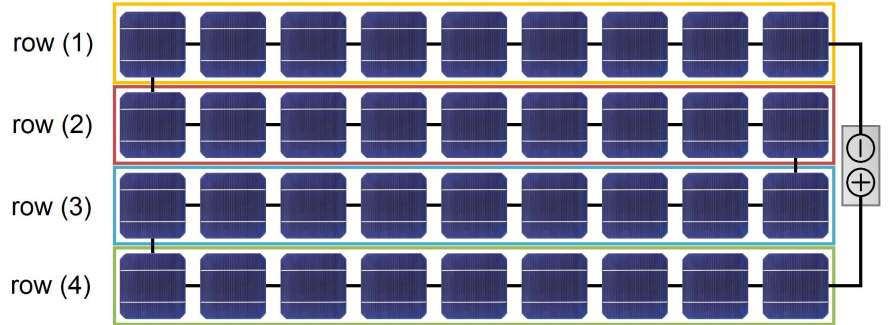

Fig. 1: Series connection of PV cells in a PV panel

In a PV simulation model, firstly, the characteristic output behaviour of a single PV cell is simulated. Then, secondly, a multiplier is used to calculate the output of a PV panel. The multiplier reflects the number of PV cells within the series connection of a panel. It is worth noting that the multiplier does not change the slope of the characteristic $I-V$ (CurrentVoltage) curve, only the scale of the voltage-axis (i.e. X-axis) [21], [22]. In this paper, we concentrate on commercial PV panels in which PV cells are connected in series.

\section{Background of Synchronized Thermography}

ST was originally developed by Leppänen et al. for the characterisation of thin films [16]. In contrast to other IRT techniques such as illuminated LIT (ILIT) and PL imaging, ST does not require uniform illumination for the device under test (DUT). These circumstances help as it is expected that under outdoor environmental conditions the irradiation on top of the PV panel will be similar but not entirely uniform. Furthermore, under outdoor environmental conditions, it is expected that the solar radiation level $(\lambda)$ changes during the duration of the measurement. Especially if the sky is overcast, the solar radiation level can change frequently between shadow and direct sunlight.

Within the early development of ST, an expensive stationary IR-camera (i.e. Optris PI 640) was used [16]. However, it was later proven that the same temperature differences can be obtained with low-cost portable IR-cameras (i.e. Flir ONE) than with expensive stationary IR-cameras [17]. For rapid diagnosis on the site of the PV power plant, a portable IR-camera which can be attached to a smartphone provides an easy opportunity for maintenance staff to carry out measurements. In [17], we used the Flir ONE with a Samsung Galaxy S4 (GT-I9506) smartphone. In this research work, we used the Flir ONE Pro (with a USB-C connector) and a Nokia 8 (TA-1004) smartphone.

\section{EXPERIMENTAL SETUP AND Procedure}

\section{A. Setup under Outdoor Environmental Conditions}

Fig. 2 shows the schematic of ST under outdoor environmental conditions. As seen in Fig. 2, an external power supply is used to forward bias PV panels and, thereby, heat them up. Heating up PV panels is a common procedure. For example, if PV panels are covered by snow or ice, then, panels are biased 


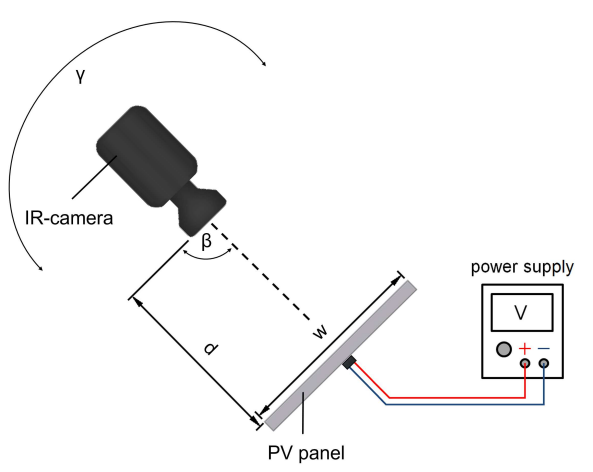

Fig. 2: Setup of ST under outdoor environmental conditions

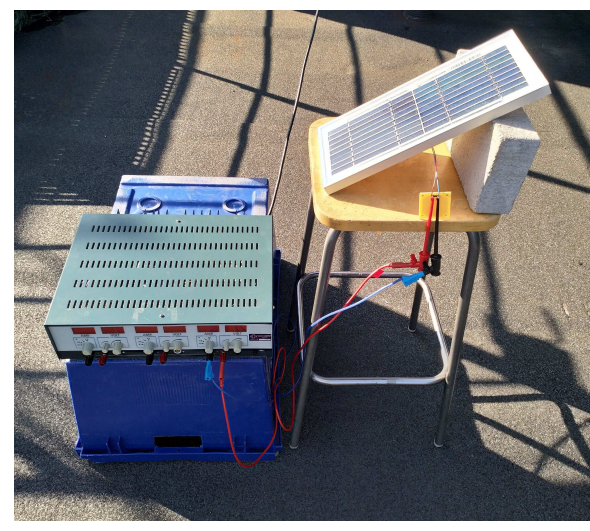

Fig. 3: ST measurement setup

forward to melt the snow or ice covering the protection glass of PV panels, allowing them again to generate electricity. Fig. 3 shows the ST measurement setup on the roof of the University of Oulu in the City of Oulu, Finland.

In previous research [16], [17] as well as in the available literature [18]-[20], as illustrated in Fig. 2, the IR-camera is aligned towards the PV panel either under a perpendicular angle $\left(\beta=90^{\circ}\right)$ or under an angle $(\beta)$ close to a perpendicular angle. However, in practice, maintenance staff should have the opportunity to obtain IR-images under various angles, which can differ significantly from a perpendicular angle. Moreover, the opportunity is given that IR-images are taken from a side angle $(\gamma)$ in which the IR-camera does not face the front side of the PV panel. Hence, in this paper, we carry out IR-imaging under different angles to verify the impact of different angles on the obtained temperature differences in IR-images.

Measurements were conducted in September when the ambient temperature was $12{ }^{\circ} \mathrm{C}$, wind speed $6 \mathrm{~m} / \mathrm{s}$, gust speed $10 \mathrm{~m} / \mathrm{s}$, and the solar radiation level was frequently varying between 100 and $400 \mathrm{~W} / \mathrm{m}^{2}$ (horizontal level). However, as seen in Fig. 3, when tilting the PV panel (i.e. the DUT) towards the sun, a higher solar radiation level of up to $650 \mathrm{~W} / \mathrm{m}^{2}$ was obtained on top of the PV panel. On the roof of the university, the measurement setup was located next to the cooling pipes of the university's air conditioning system. In addition, even though the temperature was $12{ }^{\circ} \mathrm{C}$, the asphalt shingle type roof reached a temperature of up to about $40{ }^{\circ} \mathrm{C}$.

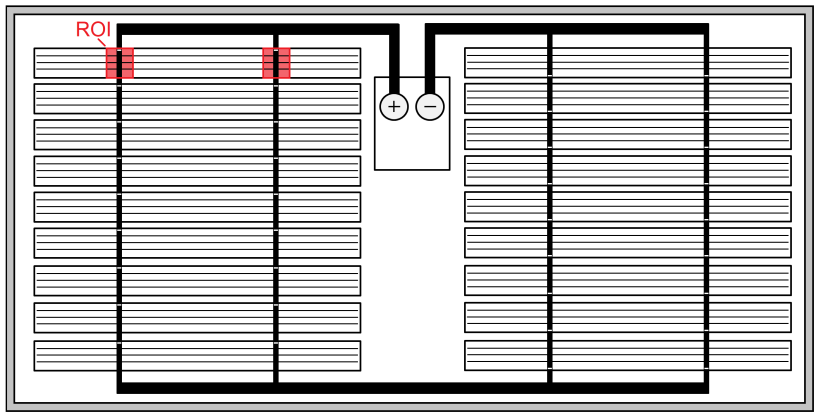

Fig. 4: Schematic of the PV panel (i.e. DUT) and ROI

Generally speaking, temperatures in the background surrounding PV panels can have an impact on the settings of the IR-camera's temperature scale, in particular when the temperatures in the background are higher than the temperatures of PV panels. In contrast, indoors, a narrower temperature scale can be used for the IR-camera in comparison to outdoors. Moreover, due to potential reflections from the protection glass of the PV panel, the IR-camera needs to be slightly tilted (i.e. $\beta$ $\neq 90^{\circ}$ ) when taking IR-images. Hence, the ROI is affected, in other words, the available resolution of the IR-image of the PV panel. The Flir ONE Pro can record IR-images in a resolution of $1440 \times 1080$ with an IR-resolution of $640 \times 480$.

\section{B. Experimental Procedure}

In this research, we concentrated on the potential practical usability of our IR-imaging method. Hence, as seen in Fig. 3, we decided not to use a measurement structure for installing the IR-camera under an optimal distance $(d)$ from the DUT in order to maximise the use of the resolution of the IR-camera as in [17] within indoor environmental conditions. Outdoors, in particular when taking IR-images of PV panels installed of the roof of buildings, it can be difficult to position an IRcamera under a certain distance $(d)$ and angle $(\beta)$ from the PV panel, for example by the use of a structure to establish a certain measurement setup. Similarly, the possibility is given that it is difficult to obtain IR-images from the front of the PV panel (i.e. $\gamma=0^{\circ}$ ).

Fig. 4 shows the series connection of PV cells inside the PV panel used within experiments (i.e. DUT). The PV panel used in the experiments is the same one as in previous research [11], [17]. In the PV panel, 18 PV cells are present, which are divided into two strings of 9 PV cells, string 1 and 2 , respectively. For rapid diagnosis, we concentrate on the connecting wire, at which the current from the PV cells is collected. Thus, multiple ROI are used; where each single ROI is located around the connecting wire of a PV cell, one on the left-hand side as well as one on the right-hand side, as illustrated in Fig. 4. From the ROI, the mean temperature $(\bar{T})$ is calculated.

In [19], a non-defect reference PV panel is used for analysing a defect PV panel. In this research, we propose a simplified version of ST, which allows to carry out analysis without the requirement of a non-defect reference sample. 
In [16], IR-images were obtained after forward biasing the PV panel with the help of an external power supply for a precise time. However, as demonstrated in [17] with the help of TRT, the PV panel only needs to be forward biased for a minimum amount of time $\left(t_{\min }\right)$, but a precise time is not needed after which an IR-image must be taken. In other words, after $t_{\min }$, the temperature differences are suitable high enough to distinguish areas with defects from areas without defects.

\section{Failure Detection}

In order to determine if a PV cell contains a potential defect, within the same PV cell, the mean temperature inside the ROI of the left-hand side $\left(\bar{T}_{l}\right)$ is compared with the mean temperature inside the ROI of the right-hand side $\left(\bar{T}_{r}\right)$. If the temperature difference between $\bar{T}_{l}$ and $\bar{T}_{r}$, in other words $\Delta \bar{T}$, exceeds $10 \%$ than the string of PV cells is perceived to contain a defect. In [17], the aim was to identify the exact location of the defect within the PV panel as well as to estimate the potential loss in output power and to investigate the impact of different types of IR-cameras on obtained temperature differences. In this work, we concentrated on quickly verifying PV cells inside panels under different angles and to flag PV panels for further inspection if a defect is suspected.

Similar to other IRT techniques [19], based on empirical research, we determine suitable values for $\Delta \bar{T}$, either as absolute or relative value. After determining a suitable value for $\Delta \bar{T}$ (i.e. the threshold temperature), we are capable of decide whether a PV cell contains a potential defect or not. As in [23], a safety margin needs to be taken into account to avoid a false-positive and false-negative detection of defects. As a result of our experiments, we found $\Delta \bar{T} \geq 10 \%$ to be suitable for flagging PV panels and, thus, assuming that they contain potential defects. As ellaborated in [17], the precise value of $\Delta \bar{T}$ can vary based on the given circumstances such as the type of DUT and used type of IR-camera, for example.

\section{Experimental Results}

Figs. 5-8 show the IR-images of the same PV panel obtained under different angles $(\gamma)$. Firstly, an IR-image was taken from the right-hand side of the PV panel $\left(\gamma \approx+45^{\circ}\right)$, similar to Fig. 3 in which the ST measurement setup is shown. As seen in Fig. 5, the temperature in string 1, the string of PV cells on the left-hand side of the PV panel, is much higher compared to string 2, the string of PV cells located on the right-hand side of the PV panel. Table I summarises the obtained measurement results for the mean temperatures $\left(\bar{T}_{i}\right)$ for each row of PV cells, row number 1 to row number 9 (i.e. $i=1,2, \ldots, 9$ ), including the temperature difference $\left(\Delta \bar{T}_{i}\right)$ for each row.

As seen in Table I the mean temperatures in string 2 are very similar and, thus, the observed temperature differences are much less than $10 \%$. Hence, it is assumed that this string of PV cells does not contain any defects. In contrast, in string 1 , large temperature differences are present which are greater than $10 \%$ and can be seen easily in the IR-image even though some reflections are caused by irradiation. When taking an IR-image in front of the PV panel $\left(\gamma \approx 0^{\circ}\right)$, in Fig. 6, large

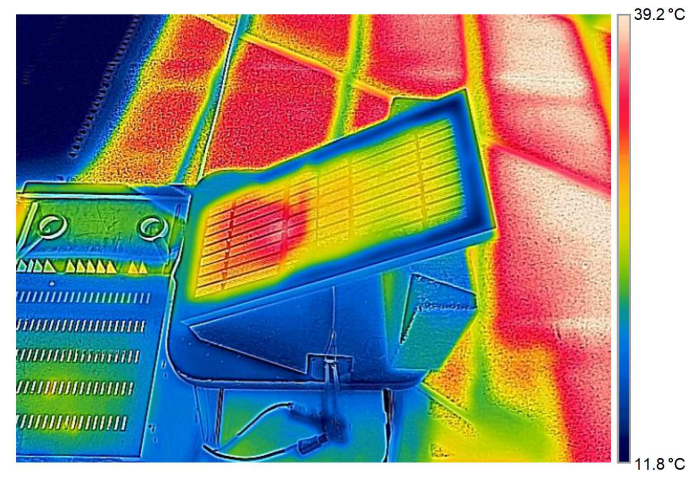

Fig. 5: Orientation 1, right-hand side of the PV panel

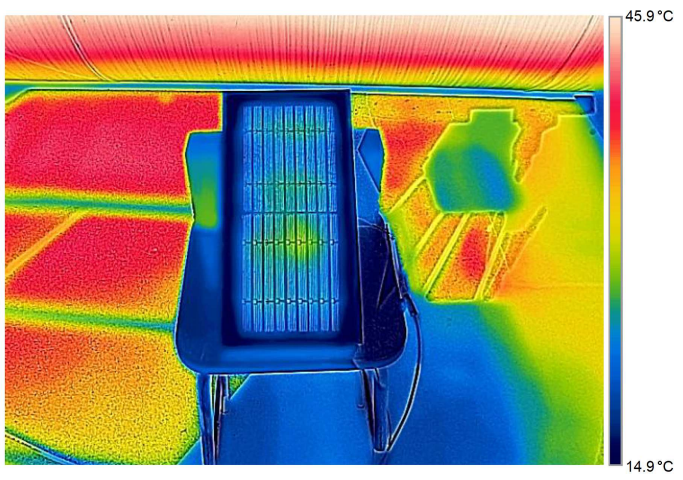

Fig. 6: Orientation 2, in front of the PV panel

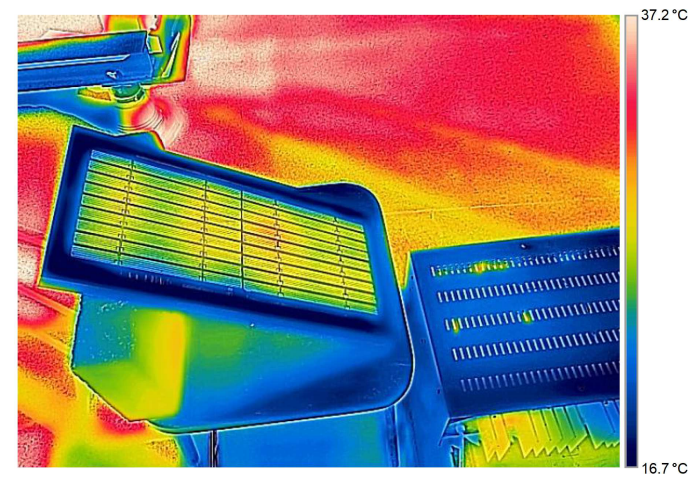

Fig. 7: Orientation 3, left-hand side of the PV panel

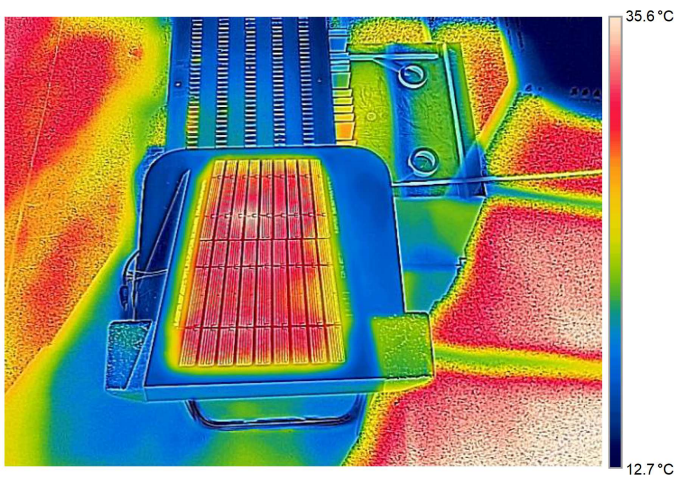

Fig. 8: Orientation 4, from top facing down to the PV panel 
TABLE I: IR-camera: Orientation 1, right-hand side of the PV panel (Fig. 5)

\begin{tabular}{|c|c|c|c|c|c|}
\hline \multicolumn{3}{|c|}{ PV string 1} & \multicolumn{3}{|c|}{ PV string 2} \\
\hline$\overline{\bar{T}}_{1, l}=31.3^{\circ} \mathrm{C}$ & $\bar{T}_{1, r}=27.5^{\circ} \mathrm{C}$ & $\left|\Delta \bar{T}_{1}\right|=3.8^{\circ} \mathrm{C} \widehat{=} 13.8 \%$ & $\bar{T}_{1, l}=26.2^{\circ} \mathrm{C}$ & $\bar{T}_{1, r}=25.4^{\circ} \mathrm{C}$ & $\left|\Delta \bar{T}_{1}\right|=0.8^{\circ} \mathrm{C} \widehat{=} 3.1 \%$ \\
\hline $\bar{T}_{2, l}=32.7^{\circ} \mathrm{C}$ & $\bar{T}_{2, r}=29.3^{\circ} \mathrm{C}$ & $\left|\Delta \bar{T}_{2}\right|=3.4^{\circ} \mathrm{C} \bumpeq 11.6 \%$ & $\bar{T}_{2, l}=27.3^{\circ} \mathrm{C}$ & $\bar{T}_{2, r}=26.6^{\circ} \mathrm{C}$ & $\left|\Delta \bar{T}_{2}\right|=0.7^{\circ} \mathrm{C} \hat{=} 2.6 \%$ \\
\hline$\overline{\bar{T}}_{3, l}=32.7^{\circ} \mathrm{C}$ & $\bar{T}_{3, r}=31.7^{\circ} \mathrm{C}$ & $\left|\Delta \bar{T}_{3}\right|=1.0{ }^{\circ} \mathrm{C} \widehat{=} 3.2 \%$ & $\bar{T}_{3, l}=28.3^{\circ} \mathrm{C}$ & $\overline{\bar{T}}_{3, r}=27.0^{\circ} \mathrm{C}$ & $\left|\Delta \bar{T}_{3}\right|=1.3{ }^{\circ} \mathrm{C} \widehat{=} 4.8 \%$ \\
\hline $\bar{T}_{4, l}=32.5^{\circ} \mathrm{C}$ & $\bar{T}_{4, r}=33.6{ }^{\circ} \mathrm{C}$ & $\left|\Delta \bar{T}_{4}\right|=1.1^{\circ} \mathrm{C} \hat{=} 3.3 \%$ & $\bar{T}_{4, l}=28.9^{\circ} \mathrm{C}$ & $\bar{T}_{4, r}=27.3^{\circ} \mathrm{C}$ & $\left|\Delta \bar{T}_{4}\right|=1.6^{\circ} \mathrm{C} \hat{=} 5.9 \%$ \\
\hline $\bar{T}_{5, l}=32.0^{\circ} \mathrm{C}$ & $\bar{T}_{5, r}=35.6^{\circ} \mathrm{C}$ & $\left|\Delta \bar{T}_{5}\right|=3.6^{\circ} \mathrm{C}=10.1 \%$ & $\bar{T}_{5, l}=28.9^{\circ} \mathrm{C}$ & $\bar{T}_{5, r}=27.8^{\circ} \mathrm{C}$ & $\left|\Delta \bar{T}_{5}\right|=1.1^{\circ} \mathrm{C} \cong 4.0 \%$ \\
\hline $\bar{T}_{6, l}=31.6^{\circ} \mathrm{C}$ & $\bar{T}_{6, r}=35.9^{\circ} \mathrm{C}$ & $\left|\Delta \bar{T}_{6}\right|=4.3^{\circ} \mathrm{C} \hat{=} 12.0 \%$ & $\bar{T}_{6, l}=28.7^{\circ} \mathrm{C}$ & $\bar{T}_{6, r}=28.1^{\circ} \mathrm{C}$ & $\left|\Delta \bar{T}_{6}\right|=0.6^{\circ} \mathrm{C} \widehat{=} 2.1 \%$ \\
\hline $\bar{T}_{7, l}=31.7^{\circ} \mathrm{C}$ & $\overline{\bar{T}}_{7, r}=34.4{ }^{\circ} \mathrm{C}$ & $\left|\Delta \bar{T}_{7}\right|=2.7^{\circ} \mathrm{C}=7.8 \%$ & $\bar{T}_{7, l}=28.0^{\circ} \mathrm{C}$ & $\bar{T}_{7, r}=27.6^{\circ} \mathrm{C}$ & $\left|\Delta \bar{T}_{7}\right|=0.4{ }^{\circ} \mathrm{C} \hat{=} 1.4 \%$ \\
\hline $\bar{T}_{8, l}=31.3{ }^{\circ} \mathrm{C}$ & $\bar{T}_{8, r}=32.0^{\circ} \mathrm{C}$ & $\left|\Delta \bar{T}_{8}\right|=0.7^{\circ} \mathrm{C} \widehat{=} 2.2 \%$ & $\bar{T}_{8, l}=27.2^{\circ} \mathrm{C}$ & $\overline{\bar{T}}_{8, r}=26.9^{\circ} \mathrm{C}$ & $\left|\Delta \bar{T}_{8}\right|=0.3^{\circ} \mathrm{C} \widehat{=} 1.1 \%$ \\
\hline $\bar{T}_{9, l}=29.9^{\circ} \mathrm{C}$ & $\overline{\bar{T}}_{9, r}=29.2^{\circ} \mathrm{C}$ & $\left|\Delta \bar{T}_{9}\right|=0.7^{\circ} \mathrm{C} \cong 2.4 \%$ & $\bar{T}_{9, l}=25.4^{\circ} \mathrm{C}$ & $\bar{T}_{9, r}=24.8^{\circ} \mathrm{C}$ & $\left|\Delta \bar{T}_{9}\right|=0.6^{\circ} \mathrm{C} \widehat{=} 2.4 \%$ \\
\hline
\end{tabular}

TABLE II: IR-camera: Orientation 2, in front of the PV panel (Fig. 6)

\begin{tabular}{|c|c|c|c|c|c|}
\hline \multicolumn{3}{|c|}{ PV string 1} & \multicolumn{3}{|c|}{ PV string 2} \\
\hline $\bar{T}_{1, l}=24.4{ }^{\circ} \mathrm{C}$ & $\bar{T}_{1, r}=25.3^{\circ} \mathrm{C}$ & $\left|\Delta \bar{T}_{1}\right|=0.9^{\circ} \mathrm{C} \hat{=} 3.6 \%$ & $\bar{T}_{1, l}=24.2{ }^{\circ} \mathrm{C}$ & $\bar{T}_{1, r}=24.2{ }^{\circ} \mathrm{C}$ & $\left|\Delta \bar{T}_{1}\right|=0.0{ }^{\circ} \mathrm{C} \hat{=} 0.0 \%$ \\
\hline $\bar{T}_{2, l}=25.4^{\circ} \mathrm{C}$ & $\overline{\bar{T}}_{2, r}=26.6^{\circ} \mathrm{C}$ & $\left|\Delta \bar{T}_{2}\right|=1.1^{\circ} \mathrm{C} \bumpeq 4.2 \%$ & $\bar{T}_{2, l}=25.4^{\circ} \mathrm{C}$ & $\bar{T}_{2, r}=25.3^{\circ} \mathrm{C}$ & $\left|\Delta \bar{T}_{2}\right|=0.1{ }^{\circ} \mathrm{C} \hat{=} 0.4 \%$ \\
\hline $\bar{T}_{3, l}=25.7^{\circ} \mathrm{C}$ & $\bar{T}_{3, r}=27.0^{\circ} \mathrm{C}$ & $\left|\Delta \bar{T}_{3}\right|=1.3^{\circ} \mathrm{C} \widehat{=} 4.8 \%$ & $\bar{T}_{3, l}=26.1^{\circ} \mathrm{C}$ & $\bar{T}_{3, r}=25.6^{\circ} \mathrm{C}$ & $\left|\Delta \bar{T}_{3}\right|=0.5{ }^{\circ} \mathrm{C} \widehat{=} 2.0 \%$ \\
\hline $\bar{T}_{4, l}=25.6^{\circ} \mathrm{C}$ & $\bar{T}_{4, r}=27.4^{\circ} \mathrm{C}$ & $\left|\Delta \bar{T}_{4}\right|=1.8^{\circ} \mathrm{C} \hat{=} 6.6 \%$ & $\bar{T}_{4, l}=26.5^{\circ} \mathrm{C}$ & $\bar{T}_{4, r}=25.9^{\circ} \mathrm{C}$ & $\left|\Delta \bar{T}_{4}\right|=0.6{ }^{\circ} \mathrm{C} \hat{=} 2.3 \%$ \\
\hline $\bar{T}_{5, l}=25.1^{\circ} \mathrm{C}$ & $\bar{T}_{5, r}=28.5^{\circ} \mathrm{C}$ & $\left|\Delta \bar{T}_{5}\right|=3.4^{\circ} \mathrm{C} \hat{=} 11.8 \%$ & $\bar{T}_{5, l}=26.6^{\circ} \mathrm{C}$ & $\bar{T}_{5, r}=26.3^{\circ} \mathrm{C}$ & $\left|\Delta \bar{T}_{5}\right|=0.3{ }^{\circ} \mathrm{C} \hat{=} 1.1 \%$ \\
\hline$\overline{\bar{T}}_{6, l}=25.0^{\circ} \mathrm{C}$ & $\overline{\bar{T}}_{6, r}=29.1^{\circ} \mathrm{C}$ & $\left|\Delta \bar{T}_{6}\right|=4.1{ }^{\circ} \mathrm{C} \cong 14.1 \%$ & $\bar{T}_{6, l}=26.7^{\circ} \mathrm{C}$ & $\overline{\bar{T}}_{6, r}=26.5^{\circ} \mathrm{C}$ & $\left|\Delta \bar{T}_{6}\right|=0.2{ }^{\circ} \mathrm{C} \hat{=} 0.8 \%$ \\
\hline $\bar{T}_{7, l}=25.2{ }^{\circ} \mathrm{C}$ & $\bar{T}_{7, r}=27.9^{\circ} \mathrm{C}$ & $\left|\Delta \bar{T}_{7}\right|=2.7^{\circ} \mathrm{C} \hat{=} 9.7 \%$ & $\bar{T}_{7, l}=26.3^{\circ} \mathrm{C}$ & $\overline{\bar{T}}_{7, r}=26.3^{\circ} \mathrm{C}$ & $\left|\Delta \bar{T}_{7}\right|=0.0{ }^{\circ} \mathrm{C} \widehat{=} 0.0 \%$ \\
\hline $\bar{T}_{8, l}=25.2{ }^{\circ} \mathrm{C}$ & $\bar{T}_{8, r}=26.4{ }^{\circ} \mathrm{C}$ & $\left|\Delta \bar{T}_{8}\right|=1.2{ }^{\circ} \mathrm{C} \hat{=} .5 \%$ & $\bar{T}_{8, l}=25.8^{\circ} \mathrm{C}$ & $\overline{\bar{T}}_{8, r}=25.9^{\circ} \mathrm{C}$ & $\left|\Delta \bar{T}_{8}\right|=0.1{ }^{\circ} \mathrm{C} \cong 0.4 \%$ \\
\hline $\bar{T}_{9, l}=23.7^{\circ} \mathrm{C}$ & $\overline{\bar{T}}_{9, r}=23.4{ }^{\circ} \mathrm{C}$ & $\left|\Delta \bar{T}_{9}\right|=0.3{ }^{\circ} \mathrm{C} \hat{=} 1.3 \%$ & $\bar{T}_{9, l}=24.2{ }^{\circ} \mathrm{C}$ & $\overline{\bar{T}}_{9, r}=24.3^{\circ} \mathrm{C}$ & $\left|\Delta \bar{T}_{9}\right|=0.1{ }^{\circ} \mathrm{C} \widehat{=} 0.4 \%$ \\
\hline
\end{tabular}

TABLE III: IR-camera: Orientation 3, left-hand side of the PV panel (Fig. 7)

\begin{tabular}{|c|c|c|c|c|c|}
\hline \multicolumn{3}{|c|}{ PV string 1} & \multicolumn{3}{|c|}{ PV string 2} \\
\hline $\bar{T}_{1, l}=25.2^{\circ} \mathrm{C}$ & $\bar{T}_{1, r}=25.6^{\circ} \mathrm{C}$ & $\left|\Delta \bar{T}_{1}\right|=0.4^{\circ} \mathrm{C} \widehat{=} 1.6 \%$ & $\bar{T}_{1, l}=24.9^{\circ} \mathrm{C}$ & $\bar{T}_{1, r}=24.4^{\circ} \mathrm{C}$ & $\left|\Delta \bar{T}_{1}\right|=0.5{ }^{\circ} \mathrm{C} \widehat{=} 2.0 \%$ \\
\hline$\overline{\bar{T}}_{2, l}=26.9^{\circ} \mathrm{C}$ & $\overline{\bar{T}}_{2, r}=27.7^{\circ} \mathrm{C}$ & $\left|\Delta \bar{T}_{2}\right|=0.8^{\circ} \mathrm{C} \cong 2.9 \%$ & $\bar{T}_{2, l}=26.3^{\circ} \mathrm{C}$ & $\bar{T}_{2, r}=26.2^{\circ} \mathrm{C}$ & $\left|\Delta \bar{T}_{2}\right|=0.1^{\circ} \mathrm{C} \widehat{=} 0.4 \%$ \\
\hline $\bar{T}_{3, l}=27.3^{\circ} \mathrm{C}$ & $\bar{T}_{3, r}=28.5^{\circ} \mathrm{C}$ & $\left|\Delta \bar{T}_{3}\right|=1.2^{\circ} \mathrm{C} \widehat{=} 4.2 \%$ & $\bar{T}_{3, l}=27.8^{\circ} \mathrm{C}$ & $\bar{T}_{3, r}=27.0^{\circ} \mathrm{C}$ & $\left|\Delta \bar{T}_{3}\right|=0.8^{\circ} \mathrm{C} \widehat{=} 3.0 \%$ \\
\hline $\bar{T}_{4, l}=27.3^{\circ} \mathrm{C}$ & $\bar{T}_{4, r}=28.7^{\circ} \mathrm{C}$ & $\left|\Delta \bar{T}_{4}\right|=1.4^{\circ} \mathrm{C} \cong 4.9 \%$ & $\bar{T}_{4, l}=28.3^{\circ} \mathrm{C}$ & $\bar{T}_{4, r}=27.1^{\circ} \mathrm{C}$ & $\left|\Delta \bar{T}_{4}\right|=1.2{ }^{\circ} \mathrm{C} \widehat{=} 4.4 \%$ \\
\hline $\bar{T}_{5, l}=26.9^{\circ} \mathrm{C}$ & $\bar{T}_{5, r}=29.5^{\circ} \mathrm{C}$ & $\left|\Delta \bar{T}_{5}\right|=2.6^{\circ} \mathrm{C} \hat{=} 8.8 \%$ & $\bar{T}_{5, l}=28.4^{\circ} \mathrm{C}$ & $\bar{T}_{5, r}=27.6^{\circ} \mathrm{C}$ & $\left|\Delta \bar{T}_{5}\right|=0.8^{\circ} \mathrm{C} \bumpeq 2.9 \%$ \\
\hline $\bar{T}_{6, l}=26.5^{\circ} \mathrm{C}$ & $\bar{T}_{6, r}=30.4^{\circ} \mathrm{C}$ & $\left|\Delta \bar{T}_{6}\right|=3.9^{\circ} \mathrm{C}=12.8 \%$ & $\bar{T}_{6, l}=28.4^{\circ} \mathrm{C}$ & $\bar{T}_{6, r}=28.1^{\circ} \mathrm{C}$ & $\left|\Delta \bar{T}_{6}\right|=0.3^{\circ} \mathrm{C} \hat{=} 1.1 \%$ \\
\hline$\overline{\bar{T}}_{7, l}=26.9^{\circ} \mathrm{C}$ & $\overline{\bar{T}}_{7, r}=29.2^{\circ} \mathrm{C}$ & $\left|\Delta \bar{T}_{7}\right|=2.3{ }^{\circ} \mathrm{C} \hat{=} 7.9 \%$ & $\overline{\bar{T}}_{7, l}=27.8^{\circ} \mathrm{C}$ & $\overline{\bar{T}}_{7, r}=27.5^{\circ} \mathrm{C}$ & $\left|\Delta \bar{T}_{7}\right|=0.3^{\circ} \mathrm{C} \hat{=} 1.1 \%$ \\
\hline $\bar{T}_{8, l}=26.9^{\circ} \mathrm{C}$ & $\bar{T}_{8, r}=27.9^{\circ} \mathrm{C}$ & $\left|\Delta \bar{T}_{8}\right|=1.0^{\circ} \mathrm{C} \hat{=3.6 \%}$ & $\bar{T}_{8, l}=27.4{ }^{\circ} \mathrm{C}$ & $\bar{T}_{8, r}=27.0^{\circ} \mathrm{C}$ & $\left|\Delta \bar{T}_{8}\right|=0.4{ }^{\circ} \mathrm{C} \widehat{=} 1.5 \%$ \\
\hline$\overline{\bar{T}}_{9, l}=25.4^{\circ} \mathrm{C}$ & $\overline{\bar{T}}_{9, r}=25.2^{\circ} \mathrm{C}$ & $\left|\Delta \bar{T}_{9}\right|=0.2^{\circ} \mathrm{C} \hat{=} 0.8 \%$ & $\bar{T}_{9, l}=25.7^{\circ} \mathrm{C}$ & $\bar{T}_{9, r}=25.1^{\circ} \mathrm{C}$ & $\left|\Delta \bar{T}_{9}\right|=0.6{ }^{\circ} \mathrm{C} \hat{=} 2.4 \%$ \\
\hline
\end{tabular}

TABLE IV: IR-camera: Orientation 4, from top facing down to the PV panel (Fig. 8)

\begin{tabular}{|c|c|c|c|c|c|}
\hline \multicolumn{3}{|c|}{ PV string 1} & \multicolumn{3}{|c|}{ PV string 2} \\
\hline $\bar{T}_{1, l}=28.1^{\circ} \mathrm{C}$ & $\bar{T}_{1, r}=29.0^{\circ} \mathrm{C}$ & $\left|\Delta \bar{T}_{1}\right|=0.9^{\circ} \mathrm{C} \hat{=} 3.1 \%$ & $\bar{T}_{1, l}=28.7^{\circ} \mathrm{C}$ & $\bar{T}_{1, r}=28.8^{\circ} \mathrm{C}$ & $\left|\Delta \bar{T}_{1}\right|=0.1^{\circ} \mathrm{C} \hat{=} 0.3 \%$ \\
\hline $\bar{T}_{2, l}=29.8^{\circ} \mathrm{C}$ & $\bar{T}_{2, r}=31.5^{\circ} \mathrm{C}$ & $\left|\Delta \bar{T}_{2}\right|=1.7^{\circ} \mathrm{C} \widehat{=} 5.4 \%$ & $\bar{T}_{2, l}=30.7^{\circ} \mathrm{C}$ & $\bar{T}_{2, r}=30.6{ }^{\circ} \mathrm{C}$ & $\left|\Delta \bar{T}_{2}\right|=0.1^{\circ} \mathrm{C} \hat{=} 0.3 \%$ \\
\hline $\bar{T}_{3, l}=30.4^{\circ} \mathrm{C}$ & $\bar{T}_{3, r}=32.2^{\circ} \mathrm{C}$ & $\left|\Delta \bar{T}_{3}\right|=1.8^{\circ} \mathrm{C} \widehat{=} 5.6 \%$ & $\bar{T}_{3, l}=31.3^{\circ} \mathrm{C}$ & $\bar{T}_{3, r}=31.4^{\circ} \mathrm{C}$ & $\left|\Delta \bar{T}_{3}\right|=0.1^{\circ} \mathrm{C} \widehat{=} 0.3 \%$ \\
\hline $\bar{T}_{4, l}=30.5^{\circ} \mathrm{C}$ & $\bar{T}_{4, r}=32.7^{\circ} \mathrm{C}$ & $\left|\Delta \bar{T}_{4}\right|=2.2^{\circ} \mathrm{C} \cong 6.7 \%$ & $\bar{T}_{4, l}=31.5^{\circ} \mathrm{C}$ & $\bar{T}_{4, r}=32.0^{\circ} \mathrm{C}$ & $\left|\Delta \bar{T}_{4}\right|=0.5^{\circ} \mathrm{C} \bumpeq 1.6 \%$ \\
\hline $\bar{T}_{5, l}=30.3^{\circ} \mathrm{C}$ & $\bar{T}_{5, r}=33.2^{\circ} \mathrm{C}$ & $\left|\Delta \bar{T}_{5}\right|=2.9^{\circ} \mathrm{C} \cong 8.7 \%$ & $\bar{T}_{5, l}=31.9^{\circ} \mathrm{C}$ & $\bar{T}_{5, r}=32.2^{\circ} \mathrm{C}$ & $\left|\Delta \bar{T}_{5}\right|=0.3^{\circ} \mathrm{C} \bumpeq 0.9 \%$ \\
\hline $\bar{T}_{6, l}=29.8^{\circ} \mathrm{C}$ & $\overline{\bar{T}}_{6, r}=34.2^{\circ} \mathrm{C}$ & $\left|\Delta \bar{T}_{6}\right|=4.4^{\circ} \mathrm{C} \hat{=} 12.9 \%$ & $\bar{T}_{6, l}=32.4^{\circ} \mathrm{C}$ & $\bar{T}_{6, r}=32.3^{\circ} \mathrm{C}$ & $\left|\Delta \bar{T}_{6}\right|=0.1^{\circ} \mathrm{C} \widehat{=} 0.3 \%$ \\
\hline$\overline{\bar{T}}_{7, l}=30.1^{\circ} \mathrm{C}$ & $\overline{\bar{T}}_{7, r}=33.8^{\circ} \mathrm{C}$ & $\left|\Delta \bar{T}_{7}\right|=3.7^{\circ} \mathrm{C} \hat{=} 10.9 \%$ & $\bar{T}_{7, l}=32.3{ }^{\circ} \mathrm{C}$ & $\overline{\bar{T}}_{7, r}=32.2^{\circ} \mathrm{C}$ & $\left|\Delta \bar{T}_{7}\right|=0.1^{\circ} \mathrm{C} \widehat{=0.3 \%}$ \\
\hline $\bar{T}_{8, l}=30.2{ }^{\circ} \mathrm{C}$ & $\bar{T}_{8, r}=32.5{ }^{\circ} \mathrm{C}$ & $\left|\Delta \bar{T}_{8}\right|=2.3{ }^{\circ} \mathrm{C} \cong 7.1 \%$ & $\bar{T}_{8, l}=32.0^{\circ} \mathrm{C}$ & $\bar{T}_{8, r}=31.6^{\circ} \mathrm{C}$ & $\left|\Delta \bar{T}_{8}\right|=0.4^{\circ} \mathrm{C} \hat{=} 1.3 \%$ \\
\hline $\bar{T}_{9, l}=29.5^{\circ} \mathrm{C}$ & $\overline{\bar{T}}_{9, r}=30.3{ }^{\circ} \mathrm{C}$ & $\left|\Delta \bar{T}_{9}\right|=0.8^{\circ} \mathrm{C} \widehat{=} 2.6 \%$ & $\bar{T}_{9, l}=31.2{ }^{\circ} \mathrm{C}$ & $\bar{T}_{9, r}=30.8^{\circ} \mathrm{C}$ & $\left|\Delta \bar{T}_{9}\right|=0.4^{\circ} \mathrm{C} \widehat{=} 1.3 \%$ \\
\hline
\end{tabular}

temperature differences can be seen in string 1. In Fig. 6, the temperature scale is wider, ranging from $14.9^{\circ} \mathrm{C}$ to 45.9 ${ }^{\circ} \mathrm{C}$, due to the heat emitted from the cooling pipes of the university's air conditioning system in the background of the IR-image. However, in Table II, the defect is clearly seen by $\Delta \bar{T}_{6}=14.1 \%$ and is actually the defect PV cell identified in previous research [17].

In Fig. 7, the IR-image is taken from the left-hand side of the PV panel $\left(\gamma \approx-45^{\circ}\right)$. Due to the different angle of the IR-camera, the temperature differences in the PV cells on the outside, row number 1 and 2 , are smaller due to less reflections caused by irradiation. The defect in row number 6 with $\Delta \bar{T}_{6}$ 
$=12.8 \%$ is clearly obtained, as seen in Table III. In Fig. 8, an IR-image is taken from top facing down to the PV panel. The observed temperature differences are higher than in the other IR-images. However, as seen in Table IV, with $\Delta \bar{T}_{6}=12.9 \%$, string 1 is correctly flagged as containing a potential defect. It is worth noting that the temperature differences in the healthy PV string, string 2, are less than $2 \%$.

\section{Discussion AND CONCLUSION}

PV panels can suffer from various defects and faults due to aging and other factors. Hence, a defect in a PV cell can occur which results into a decrease in output power of a PV panel and, thus, of an array and an entire PV power plant. Hence, it is critical to detect defects in PV panels and replace them to improve the performance of a PV power plant. Commonly, PV panels are inspected at manufacturing stage to detect defects before they are installed in the field. However, recently, thermal imaging techniques have been proposed to characterise PV panels which are already installed in the field. Hence, we concentrated on the development of an IRT technique which can be used by maintenance staff in an easy way on the site of a PV power plant.

In this paper, we investigated the potential of a simplified version of ST for carrying out rapid diagnosis on PV panels under outdoor environmental conditions. In contrast to comparable approaches in the available literature, our proposed method does not require a reference sample. In addition, the monitoring and recording of ambient conditions is not needed. Even though the irradiation is changing frequently, and IRimages are taken from various angles with the help of a lowcost portable IR-camera, defects can be clearly identified by comparing obtained temperature differences along the connecting wires of PV cells. A temperature difference of $10 \%$ allows to flag PV panels correctly for further investigations, while healthy PV panels are not flagged and identified properly.

\section{ACKNOWLEDGMENT}

Dr. Christian Schuss was funded by the Academy of Finland 6Genesis (6G) project (grant no. 318927). Prof. Tapio Fabritius is partially supported by Academy of Finlands FIRI funding (grant no. 320017).

\section{REFERENCES}

[1] Today in Energy. EIA projects world energy consumption will increase $56 \%$ by 2040 . Vol. July. Available https://www.eia.gov/todayinenergy/detail.cfm?Id=122511 [accessed 16 September 2019], 2013.

[2] D.P. van Vuuren, N. Nakicenovic, K. Riahi, A. Brew-Hammond, D. Kammen, V. Modi, and K. Smith, "An energy vision: The transformation towards sustainability - interconnected challenges and solutions", Current Opinion in Environmental Sustainability, vol. 4, issue: 1, 2012, pp. 18-34.

[3] S. Mekhilef, R. Saidur, and A. Safari, "A review on solar energy use in industries", Renewable and Sustainable Energy Reviews, vol. 15, issue: 4, pp. 1777-1790, 2011.

[4] S. Hamou, S. Zine, and R. Abdellah, "Efficiency of PV module under real working conditions", Energy Procedia, vol. 50, pp. 553-558, 2014.

[5] G.J.-P. Tevi, M.É. Faye, M. Sene, I. Faye, U. Blieske, A. Seidou Maiga, "Solar Photovoltaic Panels Failures Causing Power Losses: A Review", $7^{\text {th }}$ IEEE International Energy and Sustainability Conference (IESC), pp. $1-9,2018$.
[6] D.C. Jordan, T.J.Silverman, J.H. Wohlgemuth, S.R. Kurtz, and K.T. VanSant, "Photovoltaic failure and degradation modes", Progress in Photovoltaics: Research and Applications, vol. 25, issue: 4, pp. 318-326, 2017.

[7] W.J. Jamil, H.A. Rahman, S. Shaari, S. and Z. Salam, "Performance degradation of photovoltaic power system: Review on mitigation methods", Renewable and Sustainable Energy Reviews, vol. 67, pp. 876-891, 2017.

[8] A. Triki-Lahiani, A.B.B. Abdelghani, and I. Slama-Belkhodja, "Fault detection and monitoring systems for photovoltaic installations: A review", Renewable and Sustainable Energy Reviews, vol. 82, pp. 2680-2692, 2018.

[9] M.G. Villalva, J.R. Gazoli, and E.R. Filho, "Comprehensive Approach to Modeling and Simulation of Photovoltaic Arrays", IEEE Transactions on Power Electronics, vol. 24, issue: 5, pp. 1198-1208, 2009.

[10] L. Cristaldi, M. Faifer, M. Rossi, and F. Ponci, "A Simple Photovoltaic Panel Model: Characterization Procedure and Evaluation of the Role of Environmental Measurements", IEEE Transactions on Instrumentation and Measurement, vol. 61, issue: 10, pp. 2632-2641, 2012.

[11] C. Schuss, B. Eichberger, and T. Rahkonen, "Measurement and Verification of Photovoltaic (PV) Simulation Models", Proceedings of the IEEE International Instrumentation and Measurement Technology Conference (I2MTC), pp. 188-193, 2013.

[12] J.A. Tsanakas, L. Ha, and C. Buerhop, "Faults and infrared thermographic diagnosis in operating c-Si photovoltaic modules: A review of research and future challenges", Renewable and sustainable energy reviews, vol. 62, pp. 695-709, 2016.

[13] O. Breitenstein, "Nondestructive local analysis of current-voltage characteristics of solar cells by lock-in thermography", Solar Energy Materials and Solar Cells, vol. 95, issue: 10, pp. 2933-2936, 2011.

[14] O. Breitenstein, "Local efficiency analysis of solar cells based on lock-in thermography", Solar Energy Materials and Solar Cells, vol. 107, 2012, pp. 381-389.

[15] Z. Hameiri, A. Mahboubi Soufiani, M.K. Juhl, L. Jiang, F. Huang, Y.-B. Cheng, H. Kampwerth, J.W. Weber, M.A. Green, and T. Trupke, "Photoluminescence and electroluminescence imaging of perovskite solar cells", Progress in Photovoltaics: Research and Applications, vol. 23, issue: 12, pp. 1697-1705, 2015.

[16] C. Schuss, K. Leppänen, K. Remes, J. Saarela, T. Fabritius, B. Eichberger, and T. Rahkonen, "Detecting Defects in Photovoltaic Cells and Panels and Evaluating the Impact on Output Performances", IEEE Transactions on Instrumentation and Measurement, vol. 65, no. 5, pp. 11081119, 2016.

[17] C. Schuss, K. Remes, K. Leppänen, J. Saarela, T. Fabritius, B. Eichberger, and T. Rahkonen, "Detecting Defects in Photovoltaic Panels With the Help of Synchronized Thermography", IEEE Transactions on Instrumentation and Measurement, vol. 67, no. 5, pp. 1178-1186, 2018.

[18] M.W. Akram, G. Li, Y. Jin, X. Chen, C. Zhu, X. Zhao, M. Aleem, and A. Ahmad, "Improved outdoor thermography and processing of infrared images for defect detection in PV modules", Solar Energy, vol. 190, pp. 549-560, 2019

[19] J. Teubner, C. Buerhop, T. Pickel, J. Hauch, C. Camus, and C.J. Brabec, "Quantitative assessment of the power loss of silicon PV modules by IR thermography and its dependence on datafiltering criteria", Progress in Photovoltaics: Research and Applications, vol. 27, issue: 10, pp.856-868, 2019.

[20] G. Cipriani, V. Boscaino, V. Di Dio, F. Cardona, G. Zizzo, and S. Di Caro, S., "Application of Thermographic Techniques for the Detection of Failures on Photovoltaic Modules", IEEE International Conference on Environment and Electrical Engineering and 2019 IEEE Industrial and Commercial Power Systems Europe (EEEIC/I\&CPS Europe), pp. 1$5,2019$.

[21] M.C. Di Piazza and M. Luna and G. Petrone, and G. Spagnuolo, "ModelBased Maximum Power Curves of Solar Photovoltaic Panels Under Partial Shading Conditions", IEEE Journal of Photovoltaics, vol. 7, no: 4, pp. 1009-1016, 2017.

[22] G. Petrone, C.A. Ramos-Paja, and G. Spagnuolo. Photovoltaic Sources Modeling. John Wiley \& Sons, 2017.

[23] C. Schuss, K. Remes, K. Leppänen, J. Saarela, T. Fabritius, B. Eichberger, and T. Rahkonen, "Estimating the Impact of Defects in Photovoltaic Cells and Panels", Proceedings of the IEEE International Instrumentation and Measurement Technology Conference (I2MTC), pp. 121-126, 2016. 